\title{
Heat shock protein 90 inhibitor AUY922 attenuates platelet-derived growth factor-BB-induced migration and proliferation of vascular smooth muscle cells
}

\author{
Jisu Kim ${ }^{1, \#}$, Kang Pa Lee, ${ }^{2, \#}$, Bom Sahn Kim, Sang Ju Lee ${ }^{4}$, Byung Seok Moon ${ }^{3, *}$, and Suji Baek ${ }^{2, *}$ \\ 'Department of Sports Medicine and Science in Graduate School, Konkuk University, ${ }^{2}$ Research \& Development Center, UMUST R\&D Corporation, Seoul 05029, \\ ${ }^{3}$ Department of Nuclear Medicine, Ewha Womans University Seoul Hospital, Ewha Womans University College of Medicine, Seoul 07804, ${ }^{4}$ Department of \\ Nuclear Medicine, Asan Medical Center, University of Ulsan College of Medicine, Seoul 05505, Korea
}

\section{ARTICLE INFO}

Received December 5, 2019

Revised March 23, 2020

Accepted March 25, 2020

*Correspondence

Suji Baek

E-mail: baeksooji@konkuk.ac.kr

Byung Seok Moon

E-mail: bsmoon@ewha.ac.kr

\section{Key Words}

Atherosclerosis

AUY922

Heat shock protein 90

Platelet-derived growth factor

Vascular disease

"These authors contributed equally to this work.
ABSTRACT Luminespib (AUY922), a heat shock proteins 90 inhibitor, has anti-neoplastic and antitumor effects. However, it is not clear whether AUY922 affects events in vascular diseases. We investigated the effects of AUY922 on the platelet-derived growth factor (PDGF)-BB-stimulated proliferation and migration of vascular smooth muscle cells (VSMC). VSMC viability was detected using the XTT (2,3-bis-(2-methoxy4-nitro-5-sulfophenyl)-2H-tetrazolium-5-carboxanilide) reagent. To detect the attenuating effects of AUY922 on PDGF-BB-induced VSMCs migration in vitro, we performed the Boyden chamber and scratch wound healing assays. To identify AUY922mediated changes in the signaling pathway, the phosphorylation of protein kinase $B$ (Akt) and extracellular signal-regulated kinase (ERK) 1/2 was analyzed by immunoblotting. The inhibitory effects of AUY922 on migration and proliferation ex vivo were tested using an aortic ring assay. AUY922 was not cytotoxic at concentrations up to $5 \mathrm{nM}$. PDGF-BB-induced VSMC proliferation, migration, and sprout outgrowth were significantly decreased by AUY922 in a dose-dependent manner. AUY922 significantly reduced the PDGF-BB-stimulated phosphorylation of Akt and ERK1/2. Furthermore, PD98059 (a selective ERK1/2 inhibitor) and LY294002 (a selective Akt inhibitor) decreased VSMC migration and proliferation by inhibiting phosphorylation of Akt and ERK1/2. Greater attenuation of PDGF-BB-induced cell viability and migration was observed upon treatment with PD98059 or LY294002 in combination with AUY922. AUY922 showed anti-proliferation and anti-migration effects towards PDGF-BBinduced VSMCs by regulating the phosphorylation of ERK1/2 and Akt. Thus, AUY922 is a candidate for the treatment of atherosclerosis and restenosis.

\section{INTRODUCTION}

Cardiovascular diseases, such as atherosclerosis, hypertension, myocardial infarction, and stroke, are disorders of the blood vessels and among the leading causes of death in industrialized and developing countries because of increases in westernized eating habits [1]. The etiology of cardiovascular diseases, accepted until recently as an etiological hypothesis with evidence-based ana- tomical analysis, involves the formation of narrow blood vessels after endothelial dysfunction caused by inflammatory lesions [2]. In particular, abnormal vascular smooth muscle cell (VSMC) proliferation contributes to the poor prognosis of patients after treatment with angioplasty and stents [3]. Diverse non-clinical trials have reported that controlling abnormal VSMC migration and hyper-proliferation, which narrows the vascular wall, is a powerful strategy for inhibiting vascular diseases, including ath- (i) \$ This is an Open Access article distributed under the terms of the Creative Commons Attribution Non-Commercial License, which permits unrestricted non-commercial use, distribution, and reproduction in any medium, provided the original work is properly cited. Copyright @ Korean J Physiol Pharmacol, pISSN 1226-4512, eISSN 2093-3827
Author contributions: J.S.K. and K.P.L. contributed equally to the experimental design and performed the experiment. B.S.K. and S.J.L. contributed to the data analysis and statistical analysis. B.S.M. and S.J.B. participated in the study design and supervision. All authors participated in the preparation of the manuscript and have approved the final version. 
erosclerosis and restenosis [4].

The proliferation of VSMCs is regulated by autocrine and paracrine growth factors, which are secreted by numerous cell types, such as smooth muscle cells, endothelial cells, macrophages, and platelets [5]. Platelet-derived growth factor (PDGF)-BB is a representative growth factor that leads to the mitogens and chemoattractants of VSMCs [6]. PDGF-BB initiates cell division signals through autophosphorylation of tyrosine residues in PDGFreceptors (PDGFR) and activates multiple signaling pathways, including phosphatidylinositol 3-kinase (PI3-kinase) and mitogenactivated protein (MAP) kinases pathways [7]. Interestingly, previous studies have showed that heat shock protein 90 (HSP90), a chaperone protein, is associated with the regulation of PDGF signaling, such as protein kinase B (Akt) and extracellular signalregulated kinase (ERK) 1/2 signaling [8]. Blocking or regulating PDGF-BB signaling and associated receptors is a potential approach to delay the progression of diseases involving the blood vessels or vascular system [9].

HSP90 expression is increased in human atherosclerotic plaques [10]; some studies have showed that HSP90 inhibition can improve vascular disease via the suppression of VSMC migration and proliferation [11]. AUY922, also known as luminespib, is an HSP90 inhibitor that effectively inhibits the division of various tumor cells by inhibiting chaperone functions [12]. AUY922 inhibits cell growth and proliferation by considerably decreasing PI3-kinase and MAP kinases in HER2-positive breast cancer [13]. However, the effect of AUY922 on PDGF-BB-stimulated VSMCs is unknown. In this study, we investigated whether AUY922 can inhibit the responses of PDGF-BB-stimulated VSMCs. We found that AUY922 attenuates PDGF-BB-induced migration and proliferation in VSMCs.

\section{METHODS}

\section{Materials}

AUY922 was purchased from Selleck Chemicals (Houston, TX, USA). PDGF-BB was purchased from R\&D Systems (Minneapolis, MN, USA). Fetal bovine serum (FBS), penicillin, and streptomycin were obtained from Thermo Fisher Scientific (Waltham, MA, USA). Other chemicals were purchased from Sigma Aldrich (St. Louis, MO, USA).

\section{Animal care and isolation of VSMCs}

All animal experiments were performed in accordance with the guidelines of the ethics committee of Konkuk University (KU17196). VSMCs were isolated from the aorta of SpragueDawley (SD) rats (male, 6 weeks old), as previously described [14]. The cells were grown in Dulbecco's Modified Eagle's Medium (DMEM) supplemented with 10\% FBS, $100 \mathrm{U} / \mathrm{ml}$ penicillin, 100 $\mathrm{g} / \mathrm{ml}$ streptomycin, and $200 \mathrm{mM}$ glutamine at $37^{\circ} \mathrm{C}$ under a humidified atmosphere of $95 \%$ air $/ 5 \% \mathrm{CO}_{2}(\mathrm{v} / \mathrm{v})$.

\section{Cell viability assay}

VSMCs $\left(2 \times 10^{3}\right.$ cells/well $)$ were seeded into a 96 -well plate containing DMEM, cultured for $24 \mathrm{~h}$ and, then, incubated in FBSfree DMEM for $24 \mathrm{~h}$. Dimethyl sulfoxide was used as a solvent for AUY922, using a concentration of $0.005 \%$ as a vehicle control for cytotoxicity assays. The cells were incubated with different concentrations of AUY922 without or with PDGF-BB in FBSdeficient DMEM for $24 \mathrm{~h}$. Cell viability was determined using the 2,3-bis-(2-methoxy-4-nitro-5-sulfophenyl)-2H-tetrazolium5-carboxanilide assay kit (EZ-Cytox Cell Viability Assay Kit; Daeil Lab Service, Seoul, Korea) at $450 \mathrm{~nm}$.

\section{Scratch wound healing assay}

A scratch wound healing assay was performed according to the methods described in our previous study [14]. Briefly, VSMCs $\left(1 \times 10^{5}\right.$ cells/well $)$ were seeded into a 6-well dish and incubated in FBS-free DMEM for $24 \mathrm{~h}$. VSMCs were scratched with a 200- $\mu$ l pipette tip and washed with phosphate-buffered saline. VSMCs were incubated with or without PDGF-BB $(10 \mathrm{ng} / \mathrm{ml})$ and AUY922 (1, 2, 3, and $5 \mathrm{nM})$ in serum-free DMEM for $24 \mathrm{~h}$ and evaluated under a microscope (IX71; Olympus, Tokyo, Japan). The migration area was analyzed using ImageJ (NIH, Bethesda, MD, USA).

\section{Boyden chamber assay}

VSMCs migration was measured using the Boyden chamber assay, as previously described [14]. Briefly, VSMCs were incubated in FBS-free DMEM for $24 \mathrm{~h}$ and harvested. Next, $1 \times 10^{6} \mathrm{VSMCs} /$ $\mathrm{ml}$ in DMEM containing $0.1 \%$ bovine serum albumin (BSA) was loaded into the upper chamber. PDGF-BB $(10 \mathrm{ng} / \mathrm{ml})$ and AUY922 (1, 2, 3, and $5 \mathrm{nM})$ in $30 \mu \mathrm{l}$ serum-free DMEM containing $0.1 \%$ BSA were added to the lower chamber. VSMCs were incubated for $90 \mathrm{~min}$; then, the membranes were stained with a Diff-Quik kit (Baxter Healthcare, Miami, FL, USA). The stained cells were analyzed using ImageJ software.

\section{Immunoblotting assay}

VSMCs were seeded $\left(1 \times 10^{6}\right.$ cells $\left./ \mathrm{ml}\right)$ into a $100-\mathrm{mm}$ dish. The cells were incubated in FBS-free DMEM for $24 \mathrm{~h}$ and treated with or without PDGF-BB (10 ng/ml) and AUY922 (1, 2, 3, and $5 \mathrm{nM}$ ) for $30 \mathrm{~min}$. To determine the inhibitory effect of AUY922 on PDGF-BB-stimulated VSMCs, the cells were treated with PD98059 $(30 \mu \mathrm{M})$ and LY294002 $(20 \mu \mathrm{M})$ as positive controls (selective ERK1/2 inhibitor and Akt inhibitor, respectively) for $30 \mathrm{~min}$. After cells were lysed, proteins were separated by $12 \%$ 
polyacrylamide gel electrophoresis and transferred onto polyvinylidene fluoride membranes at $4^{\circ} \mathrm{C}$ for $2 \mathrm{~h}$. The membranes were blocked with $5 \% \mathrm{BSA}$ for $1 \mathrm{~h}$ at $25^{\circ} \mathrm{C}$ and incubated with specific antibodies, such as ERK1/2, Akt, phosphorylated ERK1/2 (pERK1/2), or $\beta$-actin (each antibody at a dilution of 1:500), for $18 \mathrm{~h}$ at $4^{\circ} \mathrm{C}$. After washing with Tris-buffered saline-Tween 20, the membranes were incubated with a 1:500 dilution of a secondary antibody (conjugated horseradish peroxidase) for $1 \mathrm{~h}$. The protein levels were detected by chemiluminescence and analyzed using ImageJ.

\section{Statistical analysis}

Data were analyzed using GraphPad Prism 5.0 (GraphPad, Inc., San Diego, CA, USA). The results are expressed as the means \pm standard deviation (SD) of at least three independent experiments $(\mathrm{n} \geq 3$ ). The results were assessed using Student's t-test and oneway analysis of variance, followed by Tukey's multiple range test. Statistical significance was considered at $\mathrm{p}<0.05$.

\section{RESULTS}

\section{Inhibitory effects of AUY922 on PDGF-BB-induced proliferation of VSMCs}

Fig. 1A shows the molecular formula and structure of AUY922 $\left(\mathrm{C}_{26} \mathrm{H}_{31} \mathrm{~N}_{3} \mathrm{O}_{5}\right)$, which has a molecular weight of $465.5 \mathrm{~g} / \mathrm{mol}$. To examine the concentration range of cytotoxicity, VSMCs were treated with different concentrations (1-50 nM) of AUY922 for $24 \mathrm{~h}$ and used the tritonX-100 (1\%) as the positive control. Fig. 1B shows the cell morphological change from the treated conditions such as vehicle, positive control, and AU922 (5 nM). The vehicle control and AUY922 (5 nM) showed similar cell morphologies. As shown in Fig. 1C, AUY922 at up to $5 \mathrm{nM}$ showed no cytotoxicity. Next, we evaluated the inhibitory effect of AUY922 on PDGF-BB-induced cell proliferation. VSMCs were treated with or without PDGF-BB (10 ng/ml) and AUY922 (1, 2, 3, and $5 \mathrm{nM})$ for $24 \mathrm{~h}$. As shown in Fig. 1D, only the PDGF-BB-treated group showed increased viability at a rate of $199.7 \pm 7.1 \%$ compared to the vehicle group. In contrast, AUY922, in the presence of PDGF$\mathrm{BB}$, significantly reduced PDGF-BB-induced VSMC growth.

\section{AUY922 attenuates the migration of PDGF-BB- induced VSMCs}

We investigated whether AUY922 can regulate PDGF-BB-
A

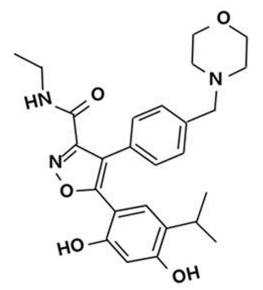

C

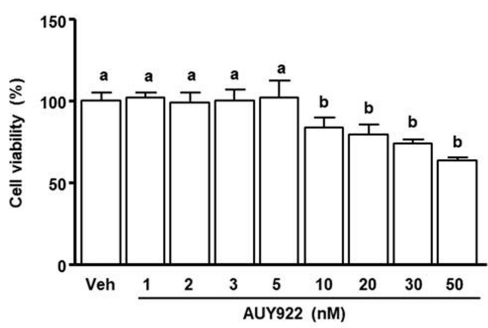

B

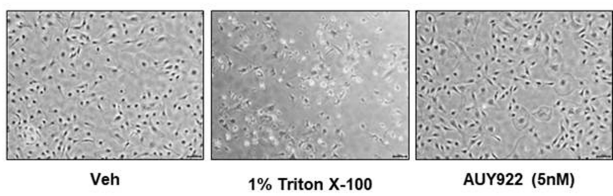

D

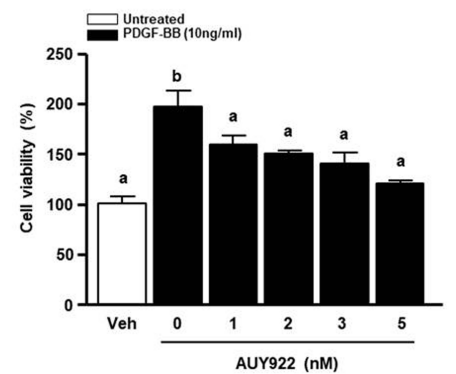

Fig. 1. Effect of AUY922 on platelet-derived growth factor (PDGF)-BB-induced vascular smooth muscle cells (VSMCs) proliferation. (A) Structure of AUY922. Molecular weight: $465.5 \mathrm{~g} / \mathrm{ml}$. (B) VSMCs were treated with $0.005 \%$ sodium dodecyl sulfate (vehicle, veh), $1 \%$ Triton X-100, and $5 \mathrm{nM}$ AUY922 for $24 \mathrm{~h}$. The cell morphologies were captured using the microscopy. Magnification, $\times 200$. (C) VSMCs $\left(2 \times 10^{4}\right.$ cells $\left./ \mathrm{ml}\right)$ were seeded into a $96-$ well plate for $24 \mathrm{~h}$. Cells were exposed to difference concentrations of AUY922 (1, 2, 3, 5, 10, 20, 30, and $50 \mathrm{nM})$ for $24 \mathrm{~h}$. Cell viability was determined using 2,3-Bis-(2-methoxy-4-nitro-5-sulfophenyl)-2H-tetrazolium-5-carboxanilide. (D) VSMCs were incubated with serum-free media for $24 \mathrm{~h}$ and treated with or without PDGF-BB $(10 \mathrm{ng} / \mathrm{ml})$ and AUY922 $(1,2,3$, and $5 \mathrm{nM})$ for $24 \mathrm{~h}$. The viability at the quiescent state is expressed as $100 \%$. Data are expressed as means \pm standard deviation. Different superscript letters indicate significant differences based on Tukey's multiple range test $(p<0.05)$. 
induced VSMC migration. To determine the inhibitory effect of AUY922 against PDGF-BB-induced VSMCs migration in the short-term, we performed a Boyden chamber assay. As shown in Fig. 2A, PDGF-BB (10 ng/ml) significantly upregulated VSMC migration, whereas AUY922 elicited the opposite effect in a dosedependent manner. Next, we confirmed the inhibitory effect of AUY922 on the migration of PDGF-BB-induced VSMCs after $24 \mathrm{~h}$ using a scratch wound healing assay. As shown in Fig. 2B, PDGF-BB-induced VSMC migration was significantly reduced by AUY922 in a dose-dependent manner. To confirm the inhibitory effect of AUY922 on VSMC migration by PDGF-BB, we performed an aortic sprout outgrowth assay. As shown in Fig. 2C, AUY922 decreased PDGF-BB-induced aortic ring outgrowth in dose-dependent manner.

\section{AUY922 reduces AKT and ERK1/2 phosphorylation in PDGF-BB-stimulated VSMCs}

HSP90 activation of Akt and ERK1/2 phosphorylation is related to the abnormal migration and proliferation of VSMCs [11]. Accordingly, we analyzed the effect of AUY922 on Akt and ERK1/2 phosphorylation in PDGF-BB-stimulated VSMCs by western blotting. As shown in Fig. 3A, PDGF-BB-induced ERK1/2 phosphorylation $(341.1 \pm 16.8 \%)$ was attenuated in a dose-dependent manner to $110 \pm 5.4 \%, 113.4 \pm 6.3 \%$, and $184.9 \pm$ $8.5 \%$ after treatment with 2, 3, and $5 \mathrm{nM}$ AUY922, respectively. With regard to the phosphorylation of Akt, protein levels in the PDGF-BB-treated group were increased by $403.9 \pm 22.9 \%$, whereas in cells treated with AUY922, intensities were increased by $268.2 \pm 24.2 \%, 207.4 \pm 19.5 \%$, and $137.1 \pm 12.5 \%$ after treatment with 2, 3, and $5 \mathrm{nM}$ AUY922, respectively. Furthermore, to confirm the pathways involved in the AUY922-mediated inhibition of PDGF-BB-induced VSMCs, the cells were treated with an ERK1/2 inhibitor (PD98059) and Akt inhibitor (LY294002). As shown in Fig. 3B, ERK1/2 phosphorylation was increased to 326.3 $\pm 8.7 \%$ in the presence of PDGF-BB. AUY922, PD98059, and LY294002 reduced the phosphorylation of ERK1/2 to $173.1 \pm 7.9 \%$, $135.91 \pm 9.9 \%$, and $77.3 \pm 18.4 \%$, respectively, compared to levels in the group treated with PDGF-BB alone. Additionally, PDGF$\mathrm{BB}$ induced the phosphorylation of Akt to $322.9 \pm 22.9 \%$, and the phosphorylation level was significantly reduced by AUY922 and LY294002 to $190.9 \pm 7.1 \%$ and $160.1 \pm 14.9 \%$, respectively.
A

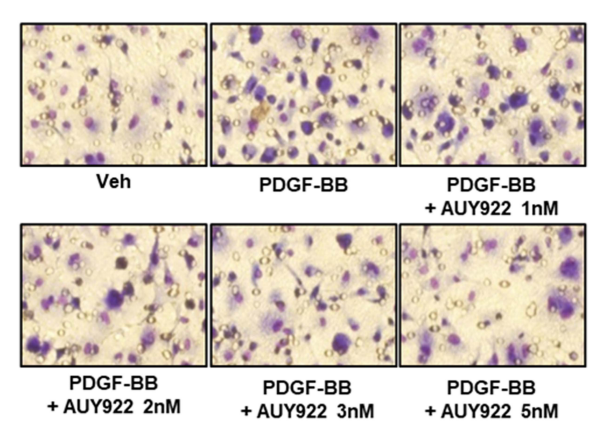

B
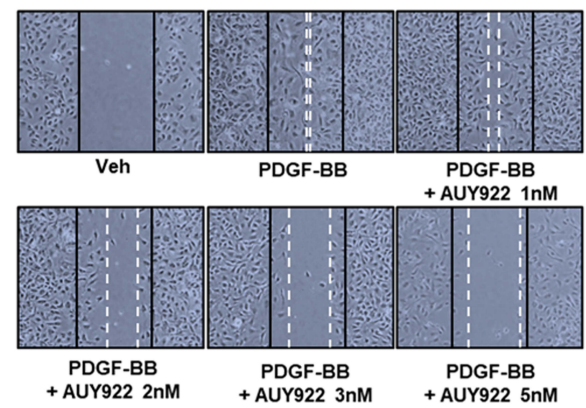

C
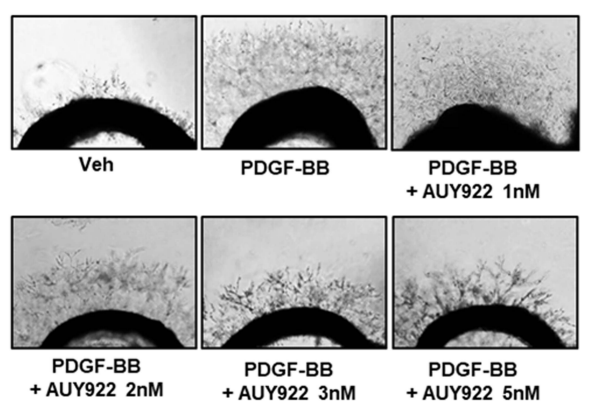
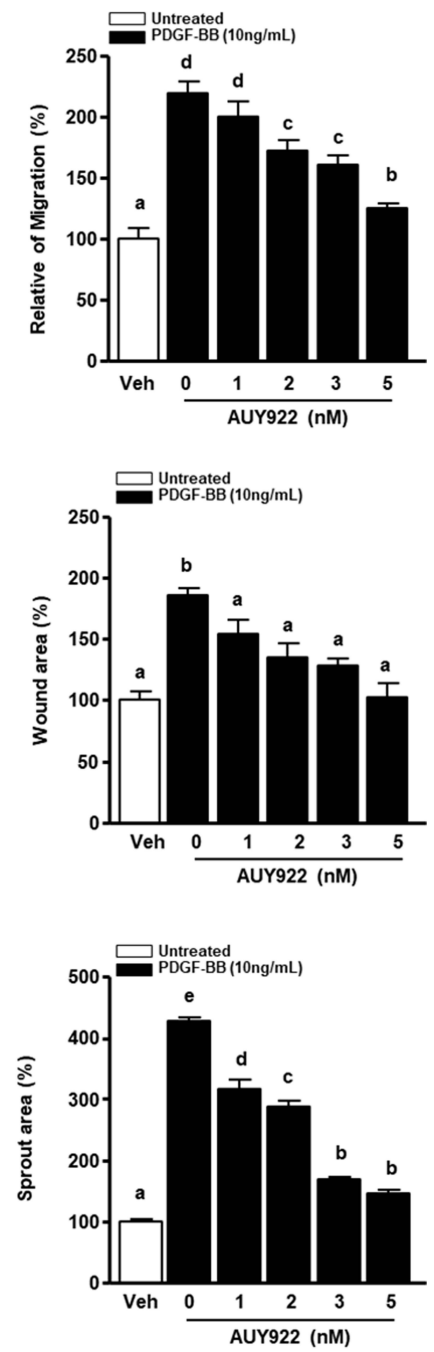

Fig. 2. Effect of AUY922 on plateletderived growth factor (PDGF)-BBinduced in vitro and ex vivo models. (A) Vascular smooth muscle cells (VSMCs) treated with AUY922 (1, 2, 3, and $5 \mathrm{nM}$ ) for $90 \mathrm{~min}$ at $37^{\circ} \mathrm{C}$. Cells were stained using a Diff-Quik Kit. (B) Cells were scratched with 200- $\mu$ lips and cotreated with PDGF-BB $(10 \mathrm{ng} / \mathrm{ml})$ and AUY922 (1, 2, 3, and $5 \mathrm{nM}$ ) for $24 \mathrm{~h}$. The black solid line shows the scratch at 0 $\mathrm{h}$ and the white dotted line shows the scratch at $24 \mathrm{~h}$. The wound healing area is expressed as $100 \%$. Data are expressed as means \pm standard deviation (SD). *Significant difference compared to the PDGF-BB group $(p<0.05)$. (C) Rat aortas were sliced to obtain 1-mm sections and embedded in Matrigel. The aortic rings were treated with or without PDGF-BB (10 ng/ml) and AUY922 (1, 2, 3, and $5 \mathrm{nM}$ ) for 4 days. The sprout area in the vehicle (veh) group is expressed as $100 \%$. The photographs were captured using the microscopy. Magnification, $\times 200$. Data are expressed as means \pm SD. Different superscript letters indicate significant differences based on Tukey's multiple range test $(p<0.05)$. 
A

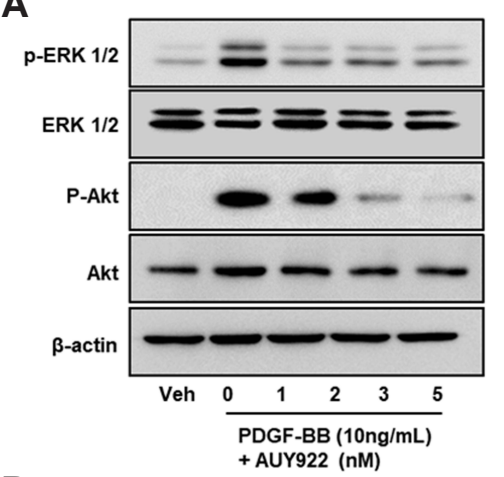

B

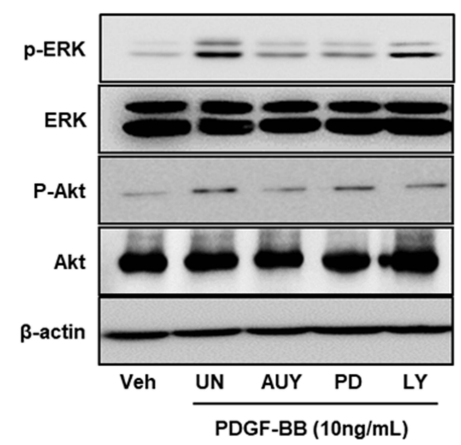

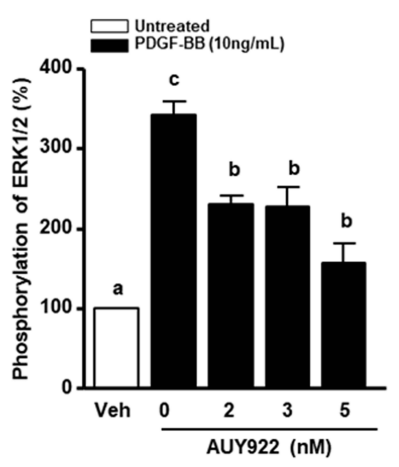
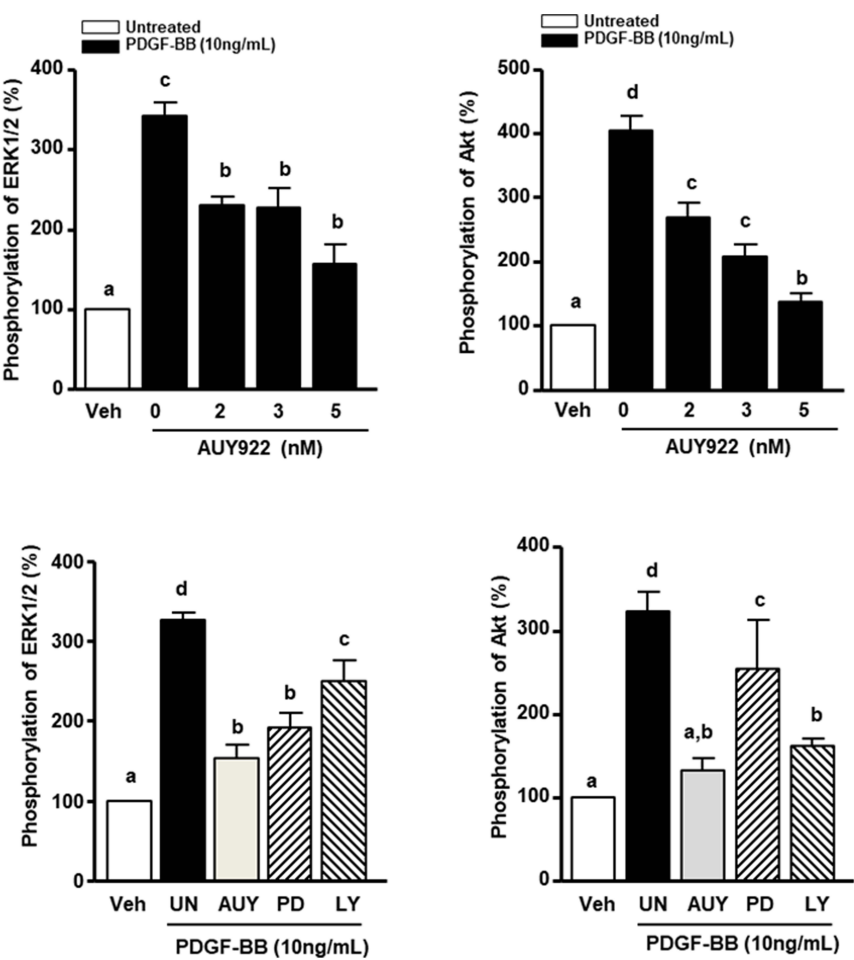

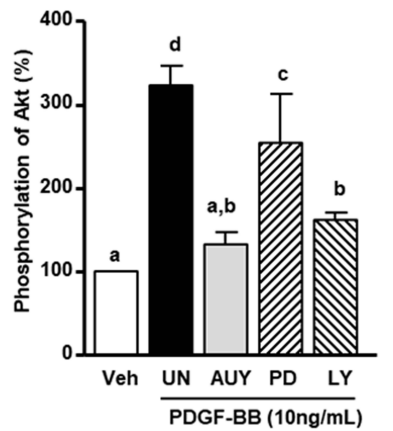

Fig. 3. Western blot analysis of extracellular signal-regulated kinase (ERK) $1 / 2$ and Akt phosphorylation. (A) Vascular smooth muscle cells (VSMCs) were incubated in serum-free media and stimulated with platelet-derived growth factor (PDGF)-BB (10 ng/ml) and AUY922 (2, 3, and $5 \mathrm{nM}$ ) for $15 \mathrm{~min}$. The cell lysates were separated by SDS-PAGE. Protein expression was detected using specific antibodies, such as anti-phosphorylated (p) ERK1/2, p-ERK1/2, Akt, and p-Akt. Graphs show the intensity of p-ERK1/2 and p-Akt, respectively. (B) VSMCs were stimulated in the presence or absence of PDGF-BB (10 ng/ml), PD98059 (30 $\mu \mathrm{M})$, LY294002 (20 $\mu \mathrm{M})$, and AUY922 $(5 \mathrm{nM})$ for $30 \mathrm{~min}$. Cells were lysed and protein expression was analyzed by western blotting. Data in graphs correspond to the images on the left. The viability at the quiescent state is expressed as $100 \%$. Data are expressed as means \pm standard deviation. Different superscript letters indicate significant differences based on Tukey's multiple range test $(p<0.05)$. Veh, vehicle.

\section{Role of AUY922 in PDGF-BB-stimulated VSMCs}

We further performed a cell viability assay and a Boyden chamber assay. Fig. 4A shows that PDGF-BB-induced VSMC proliferation was reduced to basal levels upon treatment with PD98059 $(30 \mu \mathrm{M})$ and AUY922 (5 nM). Similarly, the PDGF-BB-induced increase in proliferation was diminished by the combination of LY294002 $(20 \mu \mathrm{M})$ and AUY922 $(5 \mathrm{nM})$. Combined treatment with PD98059 and AUY922 inhibited cell growth to $97.1 \pm 3.2 \%$ of the level in the negative control (PDGF-BB alone). Following combined treatment with LY294002 and AUY922, the basal level of cell viability was $99.9 \pm 2.4 \%$ of the level in the negative control. In the Boyden chamber assay (Fig. 4B), the PDGF-BB-induced increase in migration was significantly reduced by PD98059 or LY294002 and AUY922 to basal levels. The combined treatment with PD98059 or LY294002 and AUY922 increased PDGF-induced migration to $122.6 \pm 10.0 \%$ and $110.0 \pm 10.3 \%$, respectively.

\section{DISCUSSION}

HSP90 inhibitors have anti-growth and anti-proliferation ef- fects [15]. In this study, we demonstrated that AUY922, an HSP90 inhibitor, inhibits PDGF-BB-induced increases in VSMC migration and proliferation. Moreover, AUY922 significantly reduced ERK1/2 and Akt phosphorylation in response to PDGF-BB stimulation in VSMCs. Collectively, these findings indicate that the inhibitory effect of AUY922 on HSP90 modulates downstream signaling cascades, including MAPK and Akt, to regulate PDGFBB-induced VSMC migration and proliferation.

Excessive migration and proliferation of VSMCs by PDGF-BB have been implicated in neointima formation in atherosclerosis and restenosis development [16]. PDGF-BB induces the phosphorylation of PDGFR and abnormal migration and proliferation of VSMCs [17,18]. Thus, controlling PDGFR phosphorylation and downstream signaling pathways may be a valuable strategy to treat vascular disorders [19]. Heat shock proteins are chaperone molecules that facilitate normal protein functions by controlling the folding of intercellular proteins and preventing the misfolding of newly synthesized proteins [20]. In particular, HSP90 client proteins are associated with various oncogenes, transcription factors, and steroid hormone receptors, suggesting that heat shock proteins are therapeutic targets [21]. AUY922 reduces the activation of oncogenic receptors, such as epidermal growth factor 


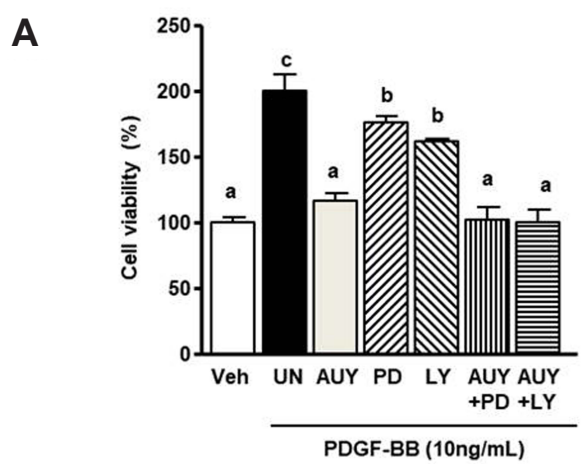

B

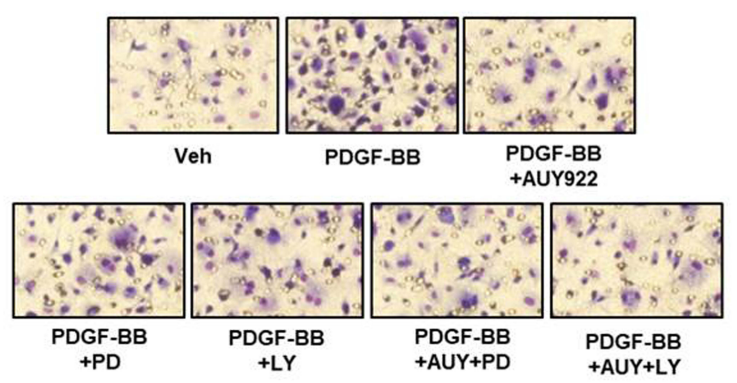

c

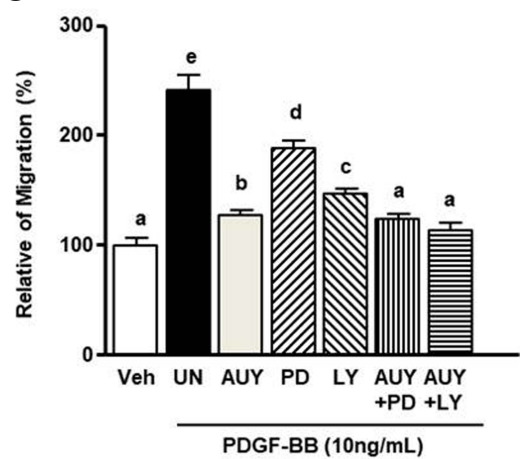

Fig. 4. Extracellular signal-regulated kinase (ERK) $1 / 2$ and Akt inhibitors decreased platelet-derived growth factor (PDGF)-BB-induced increases in vascular smooth muscle cells (VSMC) proliferation and migration. (A) VSMCs were treated with PDGF-BB, PD98059 (30 $\mu$ M), LY294002 $(20 \mu \mathrm{M})$, and AUY922 (5 nM) for $24 \mathrm{~h}$. The proliferation of VSMCs was determined by the XTT reagent. The viability at the quiescent state is expressed as 100\%. (C) Graphs were obtained by Panel B. Data are expressed as means \pm standard deviation (SD). *Significant difference compared to the PDGFBB group $(p<0.05)$. (B) VSMCs $(1 \times 106$ cells/ml) incubated with PD98059 $(30 \mu \mathrm{M})$, LY294002 $(20 \mu \mathrm{M})$, and AUY922 (5 nM) in the upper chamber and co-stimulated with PDGF-BB $(10 \mathrm{ng} / \mathrm{ml})$ in the lower chamber for $90 \mathrm{~min}$. Magnification, $\times 200$. Data are expressed as means \pm SD. Different superscript letters indicate significant differences based on Tukey's multiple range test $(p<0.05)$. Veh, vehicle.

receptor (EGFR), erb-b2 receptor tyrosine kinase 2 (ERBB2), and PDGFR in a variety of cancer cells [22]. In our study, AUY922 significantly reduced the proliferation and migration of PDGFBB-induced VSMCs in vitro and ex vivo. Therefore, we predicted that AUY922 may exert therapeutic effects in PDGF-BB-induced vascular disease via the inhibition of signaling pathways downstream of PDGFR.

To evaluate this hypothesis, we focused on the regulation of Akt and ERK1/2 phosphorylation. HSP90 strongly contribute to signaling cascades in PDGF/PDGFR. PDGF-BB activates PDGFR and downstream signaling molecules, such as Akt and ERK1/2 [23]. Some studies have reported that PDGF-BB is closely related to the excessive proliferation and migration of VSMCs via Akt and ERK1/2 phosphorylation. LY294002 (a selective Akt inhibitor) and PD98059 (a selective MAPK inhibitor) have anti-proliferation and anti-chemoattractant effects in PDGF-BB-stimulated VSMCs $[24,25]$. Our data also showed that the inhibitory effects of LY294002 or AUY922 on PDGF-induced Akt phosphorylation, and treatment with PD98059 or AUY922 efficiently downregulated the PDGF-BB-mediated overexpression of ERK1/2 phosphorylation (Fig. 3). However, the inhibitory effect indicated that AUY922 greater than PD98059 or LY294002 in the PDGFBB-induced migration and proliferation (Fig. 4). Therefore, we suggest that HSP90 inhibitors have potential therapeutic effects against vascular disorders, such as atherosclerosis and restenosis.

Reactive oxygen species (ROS) are important intermediates in normal aerobic cell metabolism; however, excessive oxidative stress can promote or interfere with physiological function [24]. Furthermore, PDGF-BB generates the oxidative stress and the secreted oxidative stressed factors, underlying HSP90 [25]. PDGFBB-induced ROS can induce the abnormal VSMC migration and proliferation through regulating the phosphorylation of ERK1/2 and Akt [26]. Oliveira et al. [27] reported that LY294002 can regulate to reduce ROS generation. Furthermore, Nguyen Thi et al. [28] reported the PD98059 induced the antioxidant enzyme such as superoxide dismutase. Our results showed that LY294002 partially inhibits ERK1/2 phosphorylation and PD98059 slightly downregulates Akt phosphorylation (Fig. 3B). However, AUY922 significantly regulates the PDGF-BB-induced the phosphorylation of Akt and ERK1/2. Therefore, AUY922 directly or indirectly regulates PDGF-BB-induced ROS or oxidative stress and antioxidant enzymes. However, further studies are needed to clarify 
the effects of HSP90 inhibitors on ROS generation in PDGF-BBstimulated VSMCs.

In conclusion, we found that AUY922 inhibits migration, proliferation, and the phosphorylation of MAPK and Akt in VSMCs in response to PDGF-BB. Additionally, AUY922 attenuated PDGF-BB-induced aortic sprout outgrowth. Therefore, AUY922, as an HSP90 inhibitor, is promising for the prevention of restenosis and atherosclerosis.

\section{ACKNOWLEDGEMENTS}

This paper was supported by the KU Research Professor Program of Konkuk University, the Basic Science Research Program through the National Research Foundation of Korea (NRF) funded by the Ministry of Science and ICT (NRF-2018R1D1A1A02085705), the Radiation Technology R\&D program through the National Research Foundation of Korea funded by the Ministry of Science and ICT (NRF2017M2A2A6A01070927) and the Korea Health Technology R\&D Project through the Korea Health Industry Development Institute (KHIDI) funded by the Ministry of Health \& Welfare (HI18C2383), Republic of Korea.

\section{CONFLICTS OF INTEREST}

The authors declare no conflicts of interest.

\section{REFERENCES}

1. Frostegård J. Immunity, atherosclerosis and cardiovascular disease. BMC Med. 2013;11:117.

2. Tousoulis D, Charakida M, Stefanadis C. Endothelial function and inflammation in coronary artery disease. Postgrad Med J. 2008;84:368-371.

3. Chaabane C, Otsuka F, Virmani R, Bochaton-Piallat ML. Biological responses in stented arteries. Cardiovasc Res. 2013;99:353-363.

4. Won KJ, Jung SH, Lee CK, Na HR, Lee KP, Lee DY, Park ES, Choi WS, Shim SB, Kim B. DJ-1/park7 protects against neointimal formation via the inhibition of vascular smooth muscle cell growth. Cardiovasc Res. 2013;97:553-561.

5. Casscells W. Smooth muscle cell growth factors. Prog Growth Factor Res. 1991;3:177-206.

6. Jawien A, Bowen-Pope DF, Lindner V, Schwartz SM, Clowes AW. Platelet-derived growth factor promotes smooth muscle migration and intimal thickening in a rat model of balloon angioplasty. J Clin Invest. 1992;89:507-511.

7. Campbell M, Trimble ER. Modification of PI3K- and MAPK-dependent chemotaxis in aortic vascular smooth muscle cells by protein kinase CbetaII. Circ Res. 2005;96:197-206.

8. Moser C, Lang SA, Stoeltzing O. Heat-shock protein 90 (Hsp90) as a molecular target for therapy of gastrointestinal cancer. Anticancer
Res. 2009;29:2031-2042.

9. Andrae J, Gallini R, Betsholtz C. Role of platelet-derived growth factors in physiology and medicine. Genes Dev. 2008;22:1276-1312.

10. Zhao Z, Wang Y, Li S, Liu S, Liu Y, Yu Y, Yang F, Xu Z, Wang G. HSP90 inhibitor 17-DMAG effectively alleviated the progress of thoracic aortic dissection by suppressing smooth muscle cell phenotypic switch. Am J Transl Res. 2019;11:509-518.

11. Kim J, Jang SW, Park E, Oh M, Park S, Ko J. The role of heat shock protein 90 in migration and proliferation of vascular smooth muscle cells in the development of atherosclerosis. J Mol Cell Cardiol. 2014;72:157-167.

12. Okamoto J, Mikami I, Tominaga Y, Kuchenbecker KM, Lin YC, Bravo DT, Clement G, Yagui-Beltran A, Ray MR, Koizumi K, He B, Jablons DM. Inhibition of Hsp90 leads to cell cycle arrest and apoptosis in human malignant pleural mesothelioma. J Thorac Oncol. 2008;3:1089-1095.

13. Chen Y, Wang X, Cao C, Wang X, Liang S, Peng C, Fu L, He G. Inhibition of HSP90 sensitizes a novel Raf/ERK dual inhibitor CY9d in triple-negative breast cancer cells. Oncotarget. 2017;8:104193104205.

14. Baek S, Lee KP, Cui L, Ryu Y, Hong JM, Kim J, Jung SH, Bae YM, Won KJ, Kim B. Low-power laser irradiation inhibits PDGF-BBinduced migration and proliferation via apoptotic cell death in vascular smooth muscle cells. Lasers Med Sci. 2017;32:2121-2127.

15. Li Y, Zhang T, Schwartz SJ, Sun D. New developments in Hsp90 inhibitors as anti-cancer therapeutics: mechanisms, clinical perspective and more potential. Drug Resist Updat. 2009;12:17-27.

16. Dzau VJ, Braun-Dullaeus RC, Sedding DG. Vascular proliferation and atherosclerosis: new perspectives and therapeutic strategies. Nat Med. 2002;8:1249-1256.

17. Kang H, Ahn DH, Pak JH, Seo KH, Baek NI, Jang SW. Magnobovatol inhibits smooth muscle cell migration by suppressing PDGF-R $\beta$ phosphorylation and inhibiting matrix metalloproteinase-2 expression. Int J Mol Med. 2016;37:1239-1246.

18. Millette E, Rauch BH, Defawe O, Kenagy RD, Daum G, Clowes AW. Platelet-derived growth factor-BB-induced human smooth muscle cell proliferation depends on basic FGF release and FGFR-1 activation. Circ Res. 2005;96:172-179.

19. Raica M, Cimpean AM. Platelet-derived growth factor (PDGF)/ PDGF receptors (PDGFR) axis as target for antitumor and antiangiogenic therapy. Pharmaceuticals (Basel). 2010;3:572-599.

20. Vabulas RM, Raychaudhuri S, Hayer-Hartl M, Hartl FU. Protein folding in the cytoplasm and the heat shock response. Cold Spring Harb Perspect Biol. 2010;2:a004390.

21. Trepel J, Mollapour M, Giaccone G, Neckers L. Targeting the dynamic HSP90 complex in cancer. Nat Rev Cancer. 2010;10:537-549.

22. Jiao Y, Ou W, Meng F, Zhou H, Wang A. Targeting HSP90 in ovarian cancers with multiple receptor tyrosine kinase coactivation. Mol Cancer. 2011;10:125.

23. Porsch H, Mehić M, Olofsson B, Heldin P, Heldin CH. Plateletderived growth factor $\beta$-receptor, transforming growth factor $\beta$ type I receptor, and CD44 protein modulate each other's signaling and stability. J Biol Chem. 2014;289:19747-19757.

24. Won KJ, Park SH, Park T, Lee CK, Lee HM, Choi WS, Kim SJ, Park PJ, Jang HK, Kim SH, Kim B. Cofilin phosphorylation mediates proliferation in response to platelet-derived growth factor-BB in rat aortic smooth muscle cells. J Pharmacol Sci. 2008;108:372-329. 
25. Namkoong S, Kim CK, Cho YL, Kim JH, Lee H, Ha KS, Choe J, Kim PH, Won MH, Kwon YG, Shim EB, Kim YM. Forskolin increases angiogenesis through the coordinated cross-talk of PKAdependent VEGF expression and Epac-mediated PI3K/Akt/eNOS signaling. Cell Signal. 2009;21:906-915.

26. ten Freyhaus H, Huntgeburth M, Wingler K, Schnitker J, Bäumer AT, Vantler M, Bekhite MM, Wartenberg M, Sauer H, Rosenkranz S. Novel Nox inhibitor VAS2870 attenuates PDGF-dependent smooth muscle cell chemotaxis, but not proliferation. Cardiovasc Res. 2006;
71:331-341.

27. Oliveira JSS, Santos GDS, Moraes JA, Saliba AM, Barja-Fidalgo TC, Mattos-Guaraldi AL, Nagao PE. Reactive oxygen species generation mediated by NADPH oxidase and PI3K/Akt pathways contribute to invasion of Streptococcus agalactiae in human endothelial cells. Mem Inst Oswaldo Cruz. 2018;113:e140421.

28. Nguyen Thi PA, Chen MH, Li N, Zhuo XJ, Xie L. PD98059 protects brain against cells death resulting from ROS/ERK activation in a cardiac arrest rat model. Oxid Med Cell Longev. 2016;2016:3723762. 